\title{
La Opinión Consultiva y los retos que se derivan para la educación religiosa en Costa Rica
}

\author{
The Advisory Opinion and the challenges that arise \\ for religious education in Costa Rica
}

\author{
Kattia Isabel Castro Flores \\ Universidad Nacional de Costa Rica
}

\begin{abstract}
Resumen
La Opinión Consultiva de la Corte Interamericana de Derechos Humanos ofrece una interpretación sobre la sexualidad humana, la identidad de género y el concepto de familia, que resulta opuesta a las promovidas por la educación religiosa. Esta discrepancia contribuye a la confrontación social que se experimenta en Costa Rica alrededor de estas temáticas. Se hace necesaria la búsqueda de caminos que promuevan una sana convivencia en medio de la diversidad social y de creencias, que constituyen la identidad costarricense.
\end{abstract}

Palabras clave: educación religiosa, sexualidad humana, identidad de género, concepto de familia, convivencia social

\begin{abstract}
The Advisory Opinion of the Inter-American Court of Human Rights offers an interpretation of human sexuality, gender identity and the concept of family, which is the opposite of those promoted by religious education. This discrepancy contributes to the social confrontation that is experienced in Costa Rica around these topics. It is necessary the search for paths that promote a healthy coexistence amid the social diversity and beliefs that constitute the Costa Rican identity.
\end{abstract}

Keywords: religious education, human sexuality, gender identity, family concept, social coexistence 


\section{Introducción}

La Corte Interamericana de Derechos Humanos emitió el 9 de enero del 2018 una resolución (OC-24-17) ${ }^{1}$ en relación a los derechos de las personas de la llamada comunidad LGTBI ${ }^{2}$. Este hecho representa un giro sustancial en el imaginario de la identidad nacional hegemónica que, por concebirse como el verdadero, goza del estatus de aceptación social. Ese imaginario ha invisibilizado, negado y rechazado las expresiones de diversidad sexual presentes en el país, al igual que lo hace con otras formas de diversidad cultural y religiosa.

La Opinión Consultiva representa un parteaguas en la historia del país. En adelante el Estado Costarricense está obligado a realizar una serie de cambios jurídicos que incorporen los lineamientos de ahí emanados. Esto implica la realización de matrimonios entre personas del mismo sexo y la consiguiente protección a estas uniones, de la misma forma que está estipulado para los matrimonios entre personas heterosexuales. También se debe realizar el cambio de nombre, según la

1 El contenido de la resolución se dio a conocer hasta el 9 de enero del 2018, aunque estaba lista desde el mes de noviembre del año anterior.

2 Con estas siglas se designan colectivamente a las personas de la llamada "diversidad sexual": lesbianas, gays, transgéneros, bisexuales, intersex (Políticas de Géneros y Diversidad Sexual de la Iglesia Luterana Costarricense 2016). identidad de género que sea asumida por las personas.

De todos los retos que se derivan de la Opinión Consultiva, quizá el mayor sea el cambio cultural mediante el cual se asuma plenamente el hecho de que también se consideran familia a los grupos conformados por personas del mismo sexo, y se respete y legitime a las personas que desean cambiar de nombre a partir de su identidad de género. En esta tarea es fundamental el papel que juega la educación en general y la educación religiosa en particular; pues a través de ellas se han promovido los valores y la moral católica como los únicos válidos, generando rechazo, descalificación y condena de todo lo que no se ajuste a estos postulados. Reconocer estas deficiencias en el modelo educativo es imprescindible para posicionarse desde otro paradigma más respetuoso e inclusivo de las diversidades.

En este sentido, es importante recuperar lo que señala Méndez (2010) en relación a los intereses de la educación.

José Mario Méndez, al exponer los argumentos que motivaron la revisión de los planes de estudio del Bachillerato en Enseñanza de la Religión en la Escuela Ecuménica de Ciencias de la Religión de la Universidad Nacional, señala que 
(...) la primera razón fue la convicción de que desde una educación religiosa anclada en una única perspectiva religiosa es imposible hacerse cargo de la diversidad de creencias y experiencias religiosas de la sociedad costarricense: sería una educación parcial y fragmentaria. (Méndez 2018, 47)

La influencia del componente religioso católico en la educación y su ascendente en la conformación de la identidad hegemónica costarricense, se remonta a la época colonial. En esta construcción no han faltado las tensiones, pero se recurre a ocultarlas para no alterar la supuesta unanimidad respecto a la identidad costarricense, construida a expensas de la negación de otros elementos poco apreciados. Acá se mencionan algunos de esos hitos con el propósito de evidenciar la complejidad de los procesos históricos que se han dado, por ejemplo, en 1886 la reforma educativa en el marco de las reformas liberales, buscó separar la educación de la tutela católica, proceso que no se consolidó del todo; luego vino la disputa entre la legislación civil y las creencias católicas en torno al tema del divorcio.

En 1907 se desencadenó en Heredia un enfrentamiento entre las autoridades religiosas y el Ministerio de Educación Pública, ya que la primera lideró una fuerte oposición a que se enseñara en el Liceo de Heredia la teoría de la evolución. A criterio de las autoridades religiosas y de parte de la feligresía cristiana, estas enseñanzas ponían en peligro la $\mathrm{fe}^{3}$. Es notoria la férrea oposición que la Iglesia católica también ha presentado a iniciativas que buscan la promoción de la planificación familiar y la educación sexual laica y científica, por considerar que estas contravienen su doctrina y su moral.

El no reconocimiento de la diversidad cultural y religiosa ha generado en el pasado episodios de tensión social. En pleno siglo XXI la Opinión Consultiva actualiza nuevamente la disputa entre los postulados de la fe y la moral católica, con la identidad diversa de la ciudadanía costarricense. Las conclusiones de la Opinión Consultiva levantan los reclamos de la comunidad católica y cristiana en general, puesto que no hay compatibilidad en sus doctrinas con los temas abordados: el concepto de familia, la sexualidad humana y la identidad de género.

Las iglesias tienen espacios propios para enseñar sus creencias y celebrar su fe, sin que esto sea adversado o impedido por nadie. El Estado Costarricense, como un estado democrático y de derecho que defiende la libertad de culto, tiene la obligación de garantizar las condiciones para que ello

3 Iván Molina Jiménez expone el conflicto en su libro La ciudad de los monos: Roberto Brenes Mesén, los católicos heredianos y el conflicto cultural de 1907 en Costa Rica. 2008. Costa Rica: EUNA. 
acontezca. Sin embargo, el conflicto se genera cuando se utilizan los espacios y recursos públicos para promover una única visión de mundo, queriendo además imponerla a toda la sociedad, lesionando los derechos de personas y grupos que no comparten los postulados y las normas que se promueven. Esto es precisamente lo que sucede con la educación religiosa, en tanto que esta materia es una asignatura del plan de estudios del sistema educativo costarricense, desde que se decretó en 1940. A lo largo de los 79 años que la asignatura ha formado parte del sistema educativo nacional, los programas han sufrido variaciones, pero ninguna de ellas en torno a los temas de la sexualidad humana y el concepto de familia. En estos puntos hay una total convergencia y unanimidad con los criterios del magisterio oficial de la Iglesia católica, mismos que difieren radicalmente de lo estipulado por la Opinión Consultiva. Los criterios disonantes, son propios de sociedades democráticas, siempre y cuando haya un reconocimiento de su existencia y el necesario respeto mutuo. En el caso de la educación religiosa, para los temas de familia y sexualidad, se toman únicamente contenidos que responden a las creencias particulares de la Iglesia católica, así como a sus valores morales. Desde su punto de vista particular, se condenan las visiones de otros actores sociales, contribuyendo con esas posturas a la confrontación social.
Las autoridades del Departamento de Educación Religiosa deben asumir su responsabilidad frente a los conflictos que generan su falta de apertura al reconocimiento de otros modelos de ver la familia y la sexualidad. Se hace urgente que en el corto plazo se realice la modificación necesaria para adaptar el Programa de Educación Religiosa a la nueva realidad jurídica y cultural del país en el campo del reconocimiento de los derechos de la población LGTBI y de las conformaciones familiares que no se ajustan al ideal de familia que promueve el dogma católico ${ }^{4}$.

\section{Antecedentes inmediatos de la consulta realizada a la Corte Interamericana de Derechos Humanos}

En Costa Rica el código de Familia data de 1974. Este a su vez es heredero de principios provenientes del Código General de 1841, donde el matrimonio tenía carácter de sacramento, en plena concordancia con los postulados de la Iglesia católica, romana y apostólica. De esta larga tradición se infiere el contenido de lo consignado en el actual Código de Familia: "Es legalmente imposible el matrimonio entre personas del mismo sexo" ${ }^{\text {. }}$. Lo anterior

4 Ver por ejemplo la Encíclica Humanae Vitae (1968), Código de Derecho Canónico (cánones 1055 a 1165) y la exhortación apostólica Familiaris Consortio (1981), el Catecismo de la Iglesia Católica (1997) (numerales 1601-1658).

5 Código de Familia de Costa Rica, capítulo 14, inciso 6 . 
deja en el desamparo jurídico a las personas del mismo sexo que están en vínculos de pareja y a las que no les son reconocidos los derechos que tienen las parejas heterosexuales. Atendiendo a esta realidad, el Gobierno de la República de Costa Rica, bajo la administración Solís Rivera presentó el 18 de mayo del 2016, una consulta a la Corte Interamericana de Derechos humanos en relación a los derechos de la población LGTBI. Específicamente se buscaba aclarar si la normativa costarricense relacionada con la identidad de género está en concordancia con la Convención Americana sobre Derechos Humanos, de la cual el Estado de Costa Rica es signatario. También se consultó en relación al reconocimiento de los derechos patrimoniales derivados de la unión entre personas del mismo sexo. Después de casi dos años de debates y consultas, que se extendieron desde el 21 de agosto del 2016 hasta el 14 de febrero del 2017, el 9 de enero del año 2018, la Corte IDH hizo público su pronunciamiento. El documento señala claramente la obligación del Estado de reconocer y garantizar todos los derechos que se deriven de un vínculo familiar entre personas del mismo sexo de conformidad con lo establecido en los artículos 11.2 y 17.1 de la Convención Americana de Derechos Humanos. Además se establece que se debe dar la posibilidad a las personas de definir su identidad sexual en los documentos oficiales por medio de un trámite expedito ${ }^{6}$.

\section{Contextoen elquesedala resolución de la Corte Interamericana de Derechos Humanos}

El fallo de la Corte IDH se dio en medio de la campaña electoral en curso, misma que se había caracterizado por mensajes centrados en la defensa de un modelo único de familia y de la oposición férrea al reconocimiento de los derechos de la población LGTBI, así como a temas relacionados con los derechos sexuales y reproductivos, y a la educación de la sexualidad desde una perspectiva laica y científica.

Lo dictaminado por la Corte IDH se convirtió rápidamente en caldo de cultivo para el recrudecimiento de una campaña electoral enfocada principalmente en alertar sobre la degradación moral de la sociedad, anunciar la destrucción de la familia, la homosexualización de la niñez, la pérdida de valores y, por ende, de la identidad costarricense.

El partido Restauración Nacional, denominado de tendencia cristiano-evangélica, se destacó por liderar la campaña en contra de lo expuesto por la Opinión Consultiva. Abiertamente contó con el apoyo decidido de otros

6 Opinión Consultiva Corte Interamericana de Derechos Humanos OC-24-2017. Recuperado de: www.corteidh.or.cr/docs/opiniones/seriea_24_esp.pdf 
partidos políticos, la Conferencia Episcopal de Costa Rica y también de la Alianza Evangélica Costarricense. A pesar de las diferencias sustantivas en otros temas, en los concernientes a la sexualidad humana y la conformación de la familia, todos estos grupos establecen gran sintonía.

El partido Restauración Nacional fue fundado por Carlos Avendaño Orozco, luego de una disputa interna dentro del partido Renovación Costarricense de donde se deriva.

En las elecciones del 2006, obtuvieron una representación en la Asamblea que se repitió en las elecciones del 2010. Para el año 2013, el partido logra inscribirse a nivel nacional y propone al mismo Carlos Avendaño como candidato presidencial para las elecciones del año siguiente. En esa oportunidad consiguen un único diputado, el señor Fabricio Alvarado, que se convertirá posteriormente en el candidato presidencial para las elecciones del 2018.

Como parte de un complejo proceso electoral que se vio favorecido, entre otras cosas, por el ambiente de polarización social a raíz de la Opinión Consultiva, la figura de Fabricio Alvarado y su discurso tuvieron un crecimiento exponencial, que lo llevó a posicionarse en unas pocas semanas entre los primeros lugares de las encuestas. Fabricio Alvarado llegó incluso a proponer el retiro de Costa Rica de la CIDH para evitar, según su parecer, que esta resolución se llegara a aplicar.

Las elecciones presidenciales se realizaron el 4 de febrero y Restauración Nacional logró la mayoría de los votos válidos emitidos. Como la cantidad de votos obtenidos no alcanzó el porcentaje mínimo establecido para alcanzar la presidencia de la República, se convocó a una segunda ronda, misma que se celebró el 1 de abril. Carlos Alvarado Quesada resultó, en esta ocasión, electo como Presidente de Costa Rica. Pese a que Fabricio Alvarado no logró llegar a la presidencia de la República, recibió un apoyo considerable y dejó en evidencia que en el país existe una fuerte oposición hacia el avance y reconocimiento de derechos humanos para la comunidad LGTBI y derechos sexuales y reproductivos, y a la idea de ampliar el concepto de familia. Lo anterior significa un enorme reto para la convivencia pacífica nacional, en tanto que las elecciones presidenciales dejaron patente que entre la población costarricense hay miradas y posturas disimiles sobre temas de alto impacto emocional y simbólico, como los señalados. El componente religioso hegemónico fue uno de los elementos más convocados en las discusiones sobre estas temáticas. La preponderancia de visiones fundamentalistas y dogmáticas contribuyó a exacerbar discursos que se materializaron en amenazas, ofensas y hasta en agresiones físicas. 
La coyuntura electoral dejó al descubierto las profundas fracturas de la sociedad costarricense, que muchas veces se maquillan con la idiosincrasia del "pura vida", una paz que se cimienta en la uniformidad y oculta las diferencias existentes pues las ve como amenazas. Lo sucedido durante el proceso electoral es un despertar un tanto violento, pero despertar al fin, de un sueño cultivado sobre falacias en torno a la identidad del ser costarricense, en donde los procesos educativos han jugado un papel preponderante sobre el cual es necesario reflexionar y tomar acciones correctivas.

Empeñarse en mantener vigente un modelo de educación religiosa que propone una única visión de mundo, negando la existencia de la alteridad es una acción poco consecuente con el escenario actual del país. La coyuntura socio-política del proceso electoral, deja en evidencia las debilidades de un modelo educativo poco inclusivo y respetuoso de las diversidades. Corresponde entonces avanzar hacia modelos que reconozcan, valoren e incluyan las diversidades en todas sus expresiones; este parece ser el único camino viable para construir relaciones respetuosas y pacíficas.

Los procesos educativos tradicionales encuentran gran resonancia en el espacio social cotidiano, donde se ven reforzados continuamente con creencias y prácticas que visualizan lo diverso como amenaza al orden establecido. Se considera lo verdadero y lo bueno a visiones de mundo que tienen mayor vigencia en el tiempo, sin analizar que su establecimiento corresponde con un proceso que ha buscado precisamente posicionar unos valores en detrimento de otros y que todo es parte de un proceso de adoctrinamiento. Méndez (2010) recuerda que la educación promueve intereses particulares. Por eso es importante romper la visión ingenua y asumir la responsabilidad que implica presentar únicamente un acercamiento de la realidad que es múltiple y compleja.

Es por lo anterior que se hace urgente una revisión y modificación del actual enfoque educativo, particularmente en educación religiosa, con el fin de rectificar y superar deficiencias que lesionan derechos fundamentales de las personas y que, por lo tanto, no abonan para la convivencia respetuosa.

\section{a. Postura de la Conferencia Episcopal de Costa Rica}

La postura de la Iglesia católica en relación al matrimonio es tajante: el vínculo matrimonial solo se puede dar entre un hombre y una mujer, tal como lo ha establecido la tradición de la Iglesia católica que eleva el vínculo matrimonial a la categoría de sacramento, por creerlo instituido por Dios. 
En reiteradas ocasiones la jerarquía eclesiástica católica se ha pronunciado en contra de aceptar el reconocimiento del matrimonio entre personas del mismo sexo. La Conferencia Episcopal de Costa Rica, mediante una carta enviada a la comisión de Asuntos Jurídicos de la Asamblea, con fecha 26 de julio de 2012, emite criterios sobre el expediente 17844 (Proyecto de ley para la regulación de las uniones de hecho entre personas del mismo sexo). En dicha carta repiten la doctrina: el matrimonio es la unión entre un hombre y una mujer, es decir una unión matrimonial monogámica heterosexual, de conformidad con los principios del cristianismo?

El comunicado de la Conferencia Episcopal, emitido el 10 de enero del 2018, en el marco de la polémica suscitada por la OC-24-17, se inscribe dentro del ya conocido discurso:

Consecuentes con estos valores extraídos de la Moral Universal y la Palabra de Dios, seguiremos enseñando que el matrimonio es un don de la creación. No hay una realidad análoga que se le pueda igualar. No es una unión cualquiera entre personas; tiene características propias e irrenunciables, que hacen del matrimonio la base de la familia y de la sociedad y por ende rechazamos los conceptos esgrimidos en la citada opinión consultiva, pues se

7 CECOR. Recuperado de: www.iglesiacr. org/2014-1/PDF/19Boletin19.pdf contraponen a la enseñanza perenne del Evangelio predicado por la Iglesia y al Bien Común de la sociedad. (CECOR 2018, numeral 7)

Más adelante, en el mismo comunicado los obispos hacen un llamado a toda la ciudadanía

(...) a estar vigilantes de las decisiones de nuestros gobernantes en los próximos días y semanas, con el fin de que actué siempre en beneficio de todos los habitantes y no solo en atención a un grupo de personas. Esta vigilancia no supone menosprecio ni discriminación a persona alguna. (CECOR 2018, numeral 8)

En la Constitución Política Costarricense, en el Artículo 75, se indica que "La Religión Católica, Apostólica, Romana, es la del Estado, el cual contribuye a su mantenimiento, sin impedir el libre ejercicio en la República de otros cultos que no se opongan a la moral universal ni a las buenas costumbres". Lo expresado en el artículo 75 , responde a una larga relación entre la Iglesia católica y el Estado costarricense, que tiene sus raíces en la historia de la conquista, la colonia y el proceso de independencia de nuestro país. La intención de la jerarquía católica ha sido mantener su hegemonía en la construcción de la identidad costarricense imponiendo sus creencias y su moral por medio de la educación en general y de la educación religiosa 
en particular ${ }^{8}$. Por condicionamientos culturales esta hegemonía no fue tan abiertamente cuestionada, pero los tiempos han cambiado y ahora está creciendo una nueva sensibilidad que no acepta las imposiciones que hacen uso del argumento de la fuerza o la autoridad religiosa. Se hace necesario recurrir al diálogo, al consenso y al respeto para lograr una convivencia pacífica en medio de la diversidad de creencias y convicciones que caracterizan la sociedad actual.

\section{b. Posicionamiento conjunto de actores cristianos}

Esta estrategia expresa un fenómeno socio-religioso de reciente data, que pone en evidencia la perdida de hegemonía de la Iglesia católica y el creciente crecimiento de otras expresiones del cristianismo en el país. A pesar de las diferencias dogmáticas y litúrgicas entre las denominaciones cristianas, son capaces de hacer causa común alrededor de los temas en los que si hay consenso. Esto da origen al posicionamiento conjunto realizado el 18 de enero del 2018, realizado entre el arzobispo José Rafael Quirós, presidente de la

8 En el texto Solano, Edgar. "La participación del clero costarricense en las campañas políticas de 1889 y 1894," Diálogos. Revista Electrónica de Historia (2010): 1-21. El texto da cuenta de la participación del clero en la política electoral, con el objetivo de restituir la enseñanza religiosa en los centros costeados por el Estado y buscando el resguardo de las órdenes religiosas en el país.
Conferencia Episcopal, y el presidente de la Federación Alianza Evangélica Costarricense, Jorge Gómez. Ambos firman un texto donde se reafirma "el valor absoluto de la vida humana desde su concepción" (numeral 1) y son enfáticos en afirmar que "la familia que se basa en el matrimonio debe encontrar el apoyo y protección del Estado. Más allá de las imposiciones internacionales" (numeral 2), lo anterior en oposición a lo dictaminado por la Opinión Consultiva.

\section{c. La postura de algunas personas legisladoras}

De la misma manera en que lo hicieron las autoridades religiosas cristianas, también algunas personas diputadas manifestaron su inconformidad con lo dictaminado por la Opinión Consultiva. Del total de 57 diputados que conforman la Asamblea Legislativa en Costa Rica, 22 enviaron una carta de protesta en contra de la respuesta de la Corte IDH. Entre los argumentos que se esgrimen para justificar la postura de rechazo, está un mal enfoque de la supuesta injerencia de los organismos de derechos humanos en la soberanía nacional.

\section{d. Los pasos dados en firme y los pasos pendientes}

El lunes 14 de mayo del 2018, en la sesión $N^{\circ} 49-2018$, el Tribunal 
Supremo de Elecciones ${ }^{9}$, después de conocer el informe técnico preparado por la comisión interna que estudió la Opinión Consultiva (OC-24/17) de la Corte Interamericana de Derechos Humanos, así como las recomendaciones registrales que esa comisión formuló, dio luz verde al cambio de nombre por identidad de género autopercibida para las personas que así lo soliciten al Registro Civil. Es decir, cada persona podrá escoger si en su documento de identidad aparece como hombre o como mujer, independientemente de su sexo biológico.

La diputada Xiomara Rodríguez, de Restauración Nacional, se mostró preocupada por la resolución del Tribunal Supremo Electoral, que permite el cambio de nombre en la cédula de identidad. En su opinión, este hecho va a agravar la actual crisis de la CCSS, pues deduce que todas las personas a las que se les facilite el cambio de nombre en su documento de identidad, van a solicitar cirugías para cambio de sexo ${ }^{10}$, apreciación que carece de sustento.

Está pendiente la puesta en práctica del matrimonio de parejas del mismo sexo, de manera que

9 Acta del TSE del día 14 de mayo del 2018. Recuperado de http://www.tse.go.cr/actas/2018/49-2018extraordinaria-del-14-de-mayo-de-2018.html

10 Recuperado de https://www.elmundo.cr/costa-rica/diputada-afirma-que-cambio-de-nombre-en-cedula-afectaria-el-sistema-de-salud/ su vínculo familiar quede protegido en las mismas condiciones que las parejas heterosexuales, tal como le expresa el Código de Familia vigente. El TSE argumenta que no le corresponde al Registro Civil autorizar o no la celebración de estos matrimonios, pues alega que su función es solamente registral. Ahora queda pendiente dejar sin efecto el artículo 14.6 del Código de Familia, que señala que el matrimonio se lleva a cabo entre personas de sexo opuesto. La anulación o derogación de ese inciso, es una tarea que le corresponde a la Sala Constitucional o a la Asamblea Legislativa respectivamente.

El 8 de agosto del 2018, mediante la Sentencia N²018-12782, la Sala Constitucional resolvió la acción de inconstitucionalidad número 15 13971-0007-CO contra el inciso 6 del artículo 14 del Código de Familia. En dicha sentencia se establece un plazo de 18 meses para que entre en vigencia el matrimonio entre personas del mismo sexo. El plazo otorgado permite a la Asamblea Legislativa tener la oportunidad de hacer lo propio para adecuar la legislación al respecto, de no hacerlo el inciso 6 del artículo 14 del Código de Familia quedará sin efecto de manera automática, una vez cumplido el tiempo establecido. 


\section{De una identidad homogénea a} la construcción de una identidad inclusiva

La conformación de la identidad costarricense ha estado marcada por fuertes intereses, en donde se marginaron muchos de los elementos de la diversidad que conforma esta nación. La educación ha sido sin duda un vehículo privilegiado para la invisiblilización y estigmatización de algunos de los grupos culturales, étnicos y religiosos, que están presentes en el territorio y lo mismo ocurre con sus aportes a la identidad nacional. La coyuntura socio-cultural y política generada por la Opinión Consultiva, dejó al descubierto el contraste entre el imaginario que exalta ciertas características del ser costarricense, como la amistad, la acogida, el respeto y la paz, así como la armonía con la naturaleza y la vida cotidiana, donde se dan las relaciones humanas en las que están presentes la violencia en todas sus formas, la misoginia, la homofobia, la xenofobia, la intolerancia a las diferencias de pensamiento y de actuación de las personas, así como un alto nivel de depredación del ambiente. Es la educación en general y la educación religiosa en particular, la que debe contribuir a mirar estas profundas fracturas, reconocerlas e incorporadas, no ya en la imagen idealizada de la identidad costarricense, sino la identidad histórica, contradictoria, rica y diversa que nos conforma.
La sociedad costarricense cuenta con una larga y profunda tradición religiosa, de fuerte acento católico conservador. Esto ha propiciado un acercamiento monocultural a muchos fenómenos y realidades diversas del acontecer nacional. Incluso la misma legislación y las políticas públicas se encuentran permeadas por esas miradas que resultan ser parciales y discriminatorias para muchas personas, al no incorporar otras miradas, expresiones, experiencias y búsquedas de sentidos de vida. La Conferencia Episcopal ha tenido el monopolio de la Educación Religiosa en el país ${ }^{11}$, lo que le ha permitido replicar y sostener sus dogmas. De manera que para muchas personas hay una total correspondencia entre la identidad nacional y los valores católicos. Esto, por otra parte, se traduce en rechazo, condena y sanción social para todo lo que no se ajuste a estos parámetros. Sin duda el rol que ha jugado la educación religiosa formal y no formal en la conformación de criterios sobre lo que se espera de las mujeres, así como la mirada sobre la sexualidad y sus roles en la vida de las personas, juega un papel fundamental. De aquí deriva la necesidad de hacer un cambio en el enfoque para abordar la diversidad religiosa y sus aportes a la identidad nacional. Es urgente también mostrar cómo los

11 Alexander Cortés, "La educación religiosa en Costa Rica. Aproximaciones teóricas del campo religioso," Revista Espiga (enero-junio 2013): 97-119. 
actores religiosos no tienen las mismas posiciones conservadoras y hay muchos que son activistas y promueven la inclusión, el respeto y la aceptación plena de la población LGTBI. Abrir las oportunidades de ampliar el panorama del conocimiento, tendrá como consecuencia el enriquecimiento en la formación de personas con criterios y visiones plurales, lo que se revertirá en espacios sociales más inclusivos y justos donde sea posible la convivencia en respeto y equidad.

La sociedad costarricense debe abocarse a consolidar la tradición democrática que le ha caracterizado y para ello es importante dar cabida en igualdad de oportunidades a los diferentes actores sociales. La Iglesia católica debe ajustar sus expectativas a un contexto donde los autoritarismos van dando paso a los diálogos desde una perspectiva intercultural donde no hay lugar para el establecimiento de jerarquías culturales porque cada una tiene pleno reconocimiento en la sinfonía de la identidad nacional.

Tanto los jerarcas de la Iglesia católica y de la Alianza Evangélica, están en su derecho de mantener su tradicional concepto de familia y de promover la identidad de género tal como la conciben, están además en todo su derecho de no aceptar nuevos enfoques. Lo que resulta inaceptable es que su oposición se convierta en una campaña de desprestigio y deslegitimación de las nuevas conformaciones familiares, pues con ello lo único que logran es generar y alimentar odios y condenas hacia esas expresiones cada vez más manifiestas en nuestra sociedad. Mantener la línea dogmática es un derecho de la institución católica y evangélica, pero igual derecho de disentir sobre sus postulados le debe ser concedido a la ciudadanía que no pertenece a la feligresía cristiana, donde además alguna de esta feligresía discrepa en algunos puntos de los dogmas cristianos en su versión católica o evangélica.

\section{Conclusiones}

Costa Rica atraviesa por un momento de gran trascendencia al querer avanzar en la extensión de los derechos humanos a poblaciones específicas. Esto debería ser motivo de alegría y celebración porque más personas van a gozar de derechos. Al otorgar derechos a las personas de la comunidad LGTBI, no se están lesionando los derechos a otras personas ni disminuyendo los derechos de nadie, por lo que esto no debería verse como una situación de crisis.

Sin embargo, en lugar de celebrar este momento, se disparan alarmas y pánico moral que provocan zozobra entre la población. Es importante señalar que los principales argumentos a los que se recurre para cuestionar e impedir que los derechos se democraticen son de corte religioso, al menos 
de una forma particular de entender lo religioso, donde lo dogmático prevalece sobre el espíritu acogedor, inclusivo y amoroso de las distintas tradiciones religiosas y espirituales, y es el juicio, la condena y el odio lo que sale a relucir.

Los argumentos de corte religioso fundamentalista fueron utilizados en otras épocas para ejercer presión y oponerse al otorgamiento de derechos a poblaciones consideradas no plenamente humanas, entre ellas: las afrodescendientes, los pueblos originarios, las mujeres, las personas con capacidades distintas. Hoy se presenta como urgente la tarea de analizar las formas categóricas utilizadas por algunas corrientes religiosas, dejando incluso de lado la esencia de las mismas que es mostrar, enseñar y practicar el amor mediante la compasión, la acogida, la hospitalidad y la hermandad universal. Posicionar una única visión de mundo es invalidar la sinfonía de caminos existentes para encontrar el sentido de la vida, que es diverso y plural como los son las culturas y las épocas históricas con sus particularidades, riquezas y limitaciones.

Aceptar la vulnerabilidad de nuestras búsquedas es exponer las facetas poco amorosas de las tradiciones religiosas que están cargadas de contradicciones en relación con lo que proponen. Asumir una actitud de humildad posibilita conversar desde un horizonte de equidad en donde las múltiples expresiones de la diversidad tengan cabida. La aceptación serena de no tener la verdad absoluta, quizá permitiría la disposición a una lectura crítica de los condicionamientos históricos y culturales que están presentes en las tradiciones religiosas y que deben ser depurados para integrar a tantas personas que hasta ahora han sido señaladas como anómalas y, por tanto, rechazadas y excluidas. Hay que enfatizar que toda vez que se predica en contra de la educación sexual inclusiva, se habla de la diversidad sexual como anormalidad y perversión, se niegan los mismos derechos a todas las personas y se usa la religión para legitimar esta injusticia se está haciendo una manipulación de Dios, haciendo de él un juez cruel y castigador y ocultando su verdadero rostro de amor, acogida y compasión.

En agosto del año 2014, la Asamblea Legislativa aprobó la modificación al Artículo 1 de la Constitución Costarricense. A partir de aquella fecha se reconoce oficialmente la dimensión multiétnica y pluricultural de la nación, lo que significa un avance jurídico sustantivo, aunque este no tenga su correspondencia en la realidad social. En adelante la tarea es lograr equiparar el reconocimiento jurídico con las prácticas cotidianas. Es precisamente en el cambio cultural donde se presenta un reto enorme y donde la educación tiene que jugar un papel fundamental. Son muchas las 
consignas que deben ser transformadas para poder avanzar hacia una sociedad igualitaria y libre de discriminación, una sociedad donde haya un real reconocimiento por la plena humanidad de todas las personas sin categorizarlas según su origen étnico, cultural, de género u orientación sexual.

La experiencia de las pasadas elecciones presidenciales, la conformación actual de la Asamblea Legislativa, con un número importante de personas que se consideran cristianas y que tienen en su agenda la defensa de la vida, la familia y los valores tradicionales, son una clara señal de la necesidad de mirar el rol que ha jugado la mirada hegemónica de la religión cristiana en la conformación de la identidad nacional imaginada. Si la proclamada y defendida identidad nacional conlleva la negación de los derechos de sectores de la sociedad, habrá que ponerla en revisión y hacer los ajustes necesarios para que se vuelva más respetuosa e inclusiva. Se debe trabajar fuertemente en el reconocimiento y la legitimidad de la diversidad, que sí es parte de la verdadera identidad nacional. Se hace necesario reconocer y hacer consciente el vínculo histórico y jurídico entre una versión del cristianismo que impone su lectura de una antropología binaria, con una visión de la sexualidad con fines procreativos, que sataniza y condena otras expresiones que no coincidan con esta. Costa Rica goza de una trayectoria con el compromiso por construir sociedades respetuosas e igualitarias y por su disponibilidad de acatar todo lo referente al marco internacional de Derechos $\mathrm{Hu}$ manos. Se debe avanzar por ese camino reforzando todas las iniciativas posibles.

Desde la educación religiosa se pueden recuperar y hacer emerger las visiones más compasivas, solidarias y amorosas con la diversidad humana, que también están presentes en las tradiciones religiosas y espirituales. La educación religiosa juega en este proceso del cambio cultural un papel importante, pues puede contribuir a romper visiones estáticas que tienen como frutos la negación de lo diverso y, por ende, un empobrecimiento en las relaciones que se pueden cultivar para una convivencia armoniosa. La educación religiosa puede dar un aporte valioso si ofrece la oportunidad de conocer los diversos horizontes espirituales y religiosos, y la contribución que estos dan a las personas para la búsqueda del sentido de la vida.

Méndez (2010) señala que los espacios educativos siempre han sido reconocidos por su capacidad para construir subjetividades acordes a los intereses de los grupos dominantes; pero también porque en ellos y en torno a ellos, es posible generar dinámicas de resistencia y transformación ${ }^{12}$.

12 José Mario Méndez, "De la intromisión a la educación: descolonizar para educar" en Ensino Religioso na Educação Básica: Fundamentos Epistemológicos e Curriculares (Florianópolis: Editora Saberes em diálogo, 2015), pp. 53-66. 
La historia muestra que, a pesar del dogmatismo imperante, se ha resistido con creatividad los embates de posturas que censuran y niegan la diversidad en todas sus formas. Los logros alcanzados a través del tiempo dan pie para renovar la esperanza y la lucha para conseguir también los necesarios cambios en el tema de los derechos humanos para la población LGTBI. La consecución de esos derechos lejos de debilitar la democracia, la fortalecen en el tanto que se amplían los derechos para grupos de personas a las cuales no se les habían otorgado. Este avance no puede verse como un retroceso, puesto que, a mayor cobertura de derechos a la población, la democracia se extiende y se fortalece.

La invitación queda hecha a todas las personas comprometidas en procesos educativos formales y no formales: desde diferentes frentes se pueden impulsar visiones que rompan con posturas sesgadas, jerárquicas y excluyentes del ser humano. De no hacerlo, se está optando por permanecer en la complicidad de defender valores y tradiciones culturales que atropellan la vida y la dignidad de las personas.

En esta tarea de construir una sociedad respetuosa e inclusiva, recae sobre sobre el Departamento de Educación Religiosa una responsabilidad particular, ya que desde el 2010 recibió un llamado de atención por parte de la Sala Constitucional (Voto 20232010:VI) para actualizar los planes de estudio conforme al nuevo escenario nacional de diversidad religiosa. En el voto se remarcó la neutralidad religiosa en materia educativa para promover y fomentar la diversidad y libertad religiosa. Méndez (2018) es de la opinión que de no acatarse este principio se "corre el riesgo de favorecer -a través de la educación religiosa- la violencia cultural y religiosa" (p. 47).

De modo que con los nuevos elementos que se derivan de la Opinión Consultiva, se refuerzan los argumentos para una revisión exhaustiva del enfoque confesional que la educación religiosa mantiene en el país. La importancia de su modificación radica en que debe dar aportes al reconocimiento, visibilización y respeto de todas las diversidades que conforman el país y con las cuales se debe construir una cultura de paz.

\section{Bibliografía}

Conferencia Episcopal de Costa Rica. 2018. Comunicado ante la respuesta de la Corte Interamericana de Derechos humanos recuperado de: http:// www.iglesiacr.org/2018/comunicado-oficial-de-la-conferencia-episcopal-de-costa-rica-ante-la-respuesta-de-la-corte-interamericana-de-derechos-humanos--cidh--.html 
Conferencia Episcopal de Costa Rica. 2012. Mensaje de la Asamblea ordinaria $\mathrm{N}^{\circ} 104$ recuperado de: http://www.iglesiacr.org/2018/ mensaje--conferencia-episcopal-de-costa-rica-de-la104-asamblea-ordinaria---6-al-10de-agosto-del-2012-.html

Conferencia Episcopal de Costa Rica. 2014. Boletín $N^{\circ} 19$. Recuperado de: www.iglesiacr.org/2014-1/ PDF/19Boletin19.pdf

Cortés, Alexander. 2013. La educación religiosa en Costa Rica. Aproximaciones teóricas del campo religioso. Revista Espiga $\mathrm{N}^{\circ} 25$ 97-119.

Costa Rica. Asamblea Legislativa. Código de Familia de Costa Rica. 1974. Disponible en: www.pgrweb.go.cr/scij/Busqueda/.../nrm_texto_completo. aspx?nValor $1=1 \ldots$

Costa Rica. Procuraduría General de la República Resolución $\mathrm{N}^{\circ}$ 2023-2010.

Costa Rica. Tribunal Supremo Electoral. 2018. Acta del 14 de mayo recuperado de http://www.tse. go.cr/actas/2018/49-2018-extraordinaria-del-14-de-mayode-2018.html

Iglesia Luterana Costarricense. 2016. Políticas de Géneros y Diversidad Sexual de la Iglesia Luterana Costarricense.

Juan Pablo II. 1981. Exhortación apostólica Familiaris Consortio.
Molina, Iván. 2008. La ciudad de los monos: Roberto Brenes Mesén, los católicos heredianos y el conflicto cultural de 1907 en Costa Rica EUNA/UCR.

Méndez, José Mario. 2015. De la intromisión a la educación: descolonizar para educar en Adecir Pozzer et al. (Organizadores), Ensino Religioso na Educação Básica: Fundamentos Epistemológicos e Curriculares. Editora Saberes em diálogo, Florianópolis, 53-66.

Méndez, José Mario. 2018. Repensar la educación religiosa en sociedades plurales: la formación profesional de docentes de educación religiosa en la Universidad Nacional. Revista Pedagógica, Chapecó, v.20, n 44, pp. 42-55 DOI: http://dx. doi.org/10.22196/rp.v20i44.4449

Pablo VI. 1968. Encíclica Humanae Vitae.

Poveda Benlloch, Antonio (Dir.). 1993. Código de Derecho Canónico. Edición bilingüe, fuentes y comentarios a todos los cánones. EDICEP C.B. Valencia, España.

Solano, Edgar. 2010. La participación del clero costarricense en las campañas políticas de 1889 y 1994. Diálogos, Revista Electrónica de Historia, v.11, no. 2 San Pedro, setiembre 2010. Recuperado de http://www.scielo.sa.cr/scielo. php?script=sci_arttext\&pi$\mathrm{d}=$ S1409-469X2010000200001 